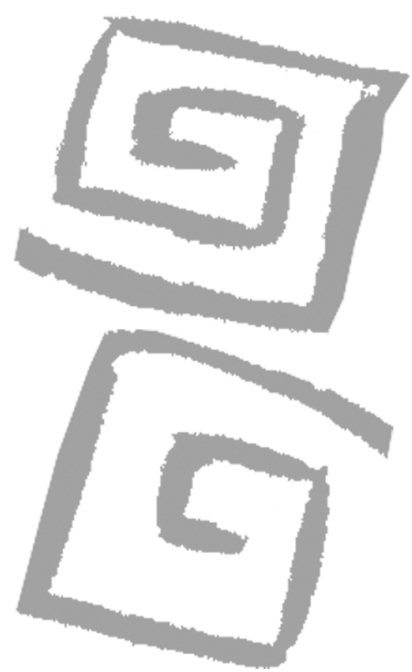

\title{
La construcción de la malnutrición infantil en la prensa escrita argentina durante la crisis de 2001
}

\author{
The construction of child malnutrition in Argentine \\ print media during the 2001 crisis
}

Demonte, Flavia ${ }^{1}$

${ }^{1}$ Licenciada en Ciencias de la Comunicación. Magíster en Políticas Sociales. Doctoranda en Ciencias Sociales, Facultad de Ciencias Sociales, Universidad de Buenos Aires (UBA). Becaria del Consejo Nacional de Investigaciones Científicas y Técnicas (CONICET), Instituto de Altos Estudios Sociales (IDAES), Universidad Nacional de San Martín (UNSAM), Argentina. flaviademonte@yahoo.com.ar
RESUMEN En la Argentina de 2001, en diferentes ámbitos (político-técnicos, académicos, mediáticos) se temía sobre el impacto que la situación de crisis podía tener en el estado nutricional de la población en situación de pobreza. Los medios de comunicación se erigieron como los actores protagónicos en el proceso de construcción del problema en ese contexto. En este artículo se analiza la construcción de la malnutrición infantil entre diciembre de 2001 y diciembre 2002, identificando las representaciones que sobre la misma organizaron el discurso de la prensa escrita en tanto actor representativo del espacio público. Metodológicamente, se utilizó un enfoque cualitativo y un tipo de investigación exploratoria-descriptiva. La técnica de recolección de la información fue la documental y el procesamiento y análisis se realizó bajo la metodología del análisis del discurso. Los principales resultados evidencian la persistencia de ciertas representaciones ligadas al problema, aun en contra de los datos epidemiológicos producidos durante el mismo período. Las representaciones identificadas, estructuradoras de las estrategias de intervención, dan cuenta de los sentidos que adquieren la alimentación, la enfermedad y el cuerpo enfermo, las medidas necesarias para "resolverla", el lugar de los actores en el espacio social y la interacción entre Estado y sociedad.

PALABRAS CLAVE Desnutrición Infantil; Recesión Económica; Medios de Comunicación; Prensa; Argentina.

ABSTRACT In the Argentina of 2001, there was great concern expressed in political, technical, academic and media circles regarding the impact the crisis could have the nutritional status of the poor. The media emerged as a major actor in the process of constructing the problem within that context. In this article the construction of child malnutrition in the period of December 2001 to December 2002 is discussed, and the representations upon which the print media, as a key actor in the public arena, based its discourse are identified. The methodology used was a qualitative approach and an exploratory-descriptive investigation. The data collection technique consisted of document analysis; the information was processed and analyzed using a discourse analysis methodology. The main results demonstrate the persistence of certain representations linked to the problem, even in contrast to epidemiological data generated during the same period. The identified representations, understood as the basis for defining intervention strategies, reveal meanings ensconced in the concepts of food, disease, and sick bodies, the measures needed to "solve the problem," the place of actors within the social network, and the interaction between the State and society. KEY WORDS Child Malnutrition; Economic Recession; Communications Media; Press; Argentina. 


\section{EL CONTEXTO POLÍTICO Y SOCIAL EN EL QUE SE CONSTRUYE UN PROBLEMA COMPLEJO}

En 2001, la Argentina experimentó una de las crisis más profundas de su historia reciente. Esta crisis, que se prolongó durante los años subsiguientes, fue el resultado de un modelo socioeconómico profundamente desigual que, de manera abrupta, hizo visible el efecto de exclusión social que venía acentuándose hacía más de 20 años a partir de la combinación de recesión con inflación (1). La ola de saqueos, los "cacerolazos" en la ciudad de Buenos Aires, la renuncia del entonces presidente de la nación y la sucesión de cinco mandatarios presidenciales en diez días fueron hechos que impactaron a nivel político, institucional y social, aún presentes en nuestra memoria (2). Los indicadores sociales evidencian la magnitud de la crisis: producto del desempleo, la devaluación y la inflación, los hogares bajo la línea de pobreza pasaron de un $28 \%$ en octubre de 2001 a un $41,4 \%$ en mayo de 2002 y a un $45,7 \%$ en octubre de 2002 , mientras que los hogares bajo la línea de indigencia pasaron de un $9,4 \%$ en octubre de 2001 a un $18 \%$ en mayo de 2002 y a un 19,5\% en octubre de 2002 (3).

La sanción de la Ley de Emergencia Pública № 25.561 en materia económica, social y administrativa a principios de 2002, daba cuenta de la situación que el país estaba atravesando. Trabajo, salud y alimentación se constituyeron en las cuestiones sociales presentes en la agenda política. De este modo, la cuestión alimentaria y la malnutrición infantil cobraron visibilidad social y política y en diferentes ámbitos (político-técnicos, académicos, mediáticos) se temía sobre el impacto de la crisis en el estado nutricional de la población en situación de pobreza y de indigencia y se preveía un aumento en la prevalencia de la desnutrición aguda, en desmedro de otras manifestaciones clínicas como la desnutrición crónica, la oculta, la obesidad o el sobrepeso. Esto trajo aparejado intensos debates acerca de la forma y el contenido de los programas alimentarios vigentes y el despliegue de diferentes acciones tendientes a intervenir sobre la problemática (promoción del autoconsumo, asistencia directa e indirecta en el marco de programas alimentarios estatales, de acciones de organizaciones sociales y comunitarias, presentaciones de diversos proyectos de ley y la sanción de la Ley de Seguridad Alimentaria No 25.724 en diciembre de 2002 por medio de la cual se creó el Programa de Nutrición y Alimentación Nacional).

A pesar de los intensos debates en ese contexto, en Argentina las cifras de la malnutrición infantil se han mantenido relativamente estables desde hace 20 años, dando cuenta de un perfil nutricional complejo. Al respecto, los estudios realizados por el Centro de Estudios sobre Nutrición Infantil (CESNI) en diferentes provincias durante los años '90, la información suministrada por la Encuesta Permanente de Hogares (EPH) de 1994 del Instituto Nacional de Estadística y Censos, y los aportes realizados por Aguirre (4) (a), ya coincidían en describir un patrón de desnutrición en el que prevalecía la desnutrición crónica por sobre la desnutrición aguda, a la vez que señalaban la importancia creciente del sobrepeso y de la obesidad como problemas de salud y nutrición pública. En 1995, el Ministerio de Salud de la Nación realizó la Primera Encuesta Antropométrica Nacional a niños de 0 a 6 años que concurrían al sistema público de salud. Y en 2002 se realizó la segunda encuesta a nivel nacional. Si bien no se evaluó la situación de todos los grupos etáreos, constituyó un hecho significativo, en la medida en que al haber utilizado la misma metodología, los resultados arrojados por ambas encuestas permiten su comparación. Al respecto, no se encontraron diferencias entre las muestras de 1995 y 2002 en los promedios de las distribuciones de peso/edad, talla/edad y peso/talla; el problema nutricional más prevalente en ambas encuestas fue la desnutrición crónica y el segundo problema nutricional en términos de frecuencia fue el sobrepeso; la prevalencia de indicadores antropométricos compatibles con desnutrición aguda se ubicaron dentro de rangos bajos. Incluso en el total de la muestra, había disminuido. Finalmente, los niños menores de 12 meses fueron los que presentaron un estado nutricional más adecuado; mientras que en el grupo de 12 a 24 meses, las prevalencias de bajo peso y baja talla para la edad aumentaron considerablemente, constituyendo el único grupo donde los valores de bajo peso/edad en 2002-2003 superaron 
los resultados de la encuesta de $1995(5,6)$. Asimismo, los datos de la Encuesta Nacional de Nutrición y Salud, realizada en el año 2003 (b), confirmaron esta tendencia epidemiológica: anemia y deficiencia de hierro, baja talla, y sobrepeso y obesidad constituyeron las alteraciones del estado nutricional más prevalentes, observadas en todos los grupos etáreos relevados (7).

A partir de estos cambios en el patrón nutricional y de los debates suscitados en el contexto de la crisis por diferentes actores, la pregunta de este estudio fue: ¿cómo se construyó el problema de la malnutrición infantil en la prensa escrita luego del quiebre político-institucional, económico, social y cultural que significó la crisis desde diciembre de 2001 hasta la sanción de la Ley № 25.724, en diciembre de 2002? Para ello, se identificaron y analizaron las representaciones que se pusieron en juego en sus discursos considerando a la prensa escrita como actor representativo del espacio público y, como tal, protagonista a la vez que condicionante de los temas y modalidades que asume la discusión en el ámbito público.

Como se señaló precedentemente, el contexto creó un clima que puso el problema de la malnutrición en la escena sociopolítica, suscitando discusiones, posicionamientos, definiciones y generando intervenciones de diferentes actores sociales (agencias del Estado, organizaciones sociales y comunitarias, redes de expertos, etc.). Ese momento particular es el que se aborda en este trabajo (c), situando la indagación en el contexto más específico de lo sucedido en el discurso de la prensa en tanto actor clave en ese proceso, sin olvidar el contexto mayor y la interrelación que se produce con otros actores y con sus discursos en el mismo espacio de la prensa. En este sentido, la prensa y los medios en general se constituyeron en el espacio analítico que condensó visiones y sentidos que han circulado en diferentes ámbitos, fundamentalmente político-técnicos.

\section{MEDIOS DE COMUNICACIÓN: ACTORES CLAVE EN LOS PROCESOS DE CONSTRUCCIÓN DE PROBLEMAS}

En la pregunta que guía este trabajo subyace una determinada forma de concebir lo social, de cómo se experimenta, se percibe, se interpreta y se conoce. Desde esta perspectiva, los problemas no están dados en la realidad para ser descubiertos y explicados, sino que se construyen a partir de complejos procesos caracterizados por la competencia y el conflicto de principios productores de representaciones que expresan diferentes intereses (8). Por lo tanto, se asume que la realidad social se construye tanto por condiciones objetivas como por la forma en que los agentes sociales perciben e interpretan el mundo que los rodea (9). En este sentido, la noción de puntos de vista de Bourdieu, hace referencia a las perspectivas, a las visiones subjetivas producidas desde un punto, desde una posición determinada en el espacio social. En otras palabras, el lugar que se ocupa en el espacio social dispone a percibir, a evaluar e interpretar el mundo de determinada manera, cristalizándose en representaciones que condicionan las prácticas de sujetos y grupos. Por otra parte, las representaciones sobre un problema -en este caso, la malnutrición infantil constituye un problema de salud complejo en el que confluyen factores socioeconómicos, culturales y psicológicos- se materializan en diversos discursos. Estos discursos no se encuentran solamente en el ámbito de "la política" como práctica circunscrita a los poderes políticos en tanto sujetos "hacedores" de políticas públicas (o prácticas, medidas, acciones), sino que se erigen como una práctica social de producción de significados que expresan categorías de aprehensión del mundo, según las diferentes perspectivas o puntos de vista de los agentes involucrados que participan en su construcción, proponiendo metas y caminos de acción posibles (10).

Si bien todos los sujetos y grupos perciben y/o experimentan problemas de diversa índole, el establecimiento de un problema como asunto de discusión pública, como merecedor de la atención y la actuación públicas (11), remite a la constitución de sujetos según relaciones de poder. Intervienen en este escenario actores provenientes de diferentes campos y, por ende, con cuotas de capital diverso que tratan de imponer y/o hegemonizar diversas definiciones acerca del problema y su contexto de referencia legítima: partidos políticos, burócratas, redes de expertos y académicos, medios masivos de comunicación, Poder Ejecutivo y Legislativo, grupos de interés y 
opinión pública $(12,8)$. Aunque conscientes de que estos actores detentan suficientes cuotas de capital -cultural, económico o social- para instalar un problema en la agenda social, los malestares sociales tienen existencia visible cuando los medios de comunicación hablan de ellos, es decir, cuando los periodistas los reconocen como tales, según intereses propios del sector del cual dependen (13). Asimismo, los medios de comunicación no solo visibilizan, instalan y construyen agendas de problemas, sino también condicionan las modalidades que asume la discusión misma en el espacio público. No obstante ello, ningún discurso puede ser analizado en forma aislada del contexto político, social, económico y cultural en el que se produce, ni como discurso "puro": por la prensa transitan múltiples actores con diversos intereses, por lo que los medios se configuran en escenarios discursivos. En otras palabras, los discursos de los medios se interrelacionan con discursos provenientes de otros campos y de otros actores que, en conjunto, contribuyen a construir la realidad en tanto constituyen y dan forma a las experiencias y vivencias cotidianas de los sujetos y grupos sociales.

\section{EL DISCURSO PERIODÍSTICO EN LA PRENSA ESCRITA: ENTRE HECHOS Y RELATOS}

Como configuradores de agendas de problemas y modeladores de las discusiones públicas, los medios de comunicación, y los periodistas que trabajan en ellos, no se constituyen en mediadores neutrales en la relación entre la información y el público. Por el contrario, las noticias están atravesadas por intereses empresariales, políticos y personales y por diversas representaciones sociales (14). Asimismo, y en tanto relatos, las noticias se construyen y el proceso de su construcción implica el despliegue de diferentes estrategias que son recurrentes en el discurso mediático a la hora de la presentación de la versión que se hace pública. La selección de los temas, el posicionamiento asumido en cada uno de ellos, su extensión y modalidad en el tratamiento, las fuentes convocadas, los sistemas clasificatorios, organizan y dan cuenta de su relevancia en un momento histórico determinado, condicionando el debate público (14).

Los temas son organizados y ubicados en determinados espacios. Las clasificaciones se realizan según los ámbitos de ocurrencia de los acontecimientos y responden a un interés común o a un interés sectorial (15). Cuando la importancia del tema lo amerita, puede presentarse de manera serializada, es decir, tematizado durante varios períodos de tiempo, porque constituye un problema grave o abierto que requiere un desarrollo y que produce otros hechos conexos, por lo que debe ser continuamente alimentado con nueva información.

Las fuentes informativas tienen el doble resultado, más o menos explícito, de otorgar verosimilitud al hecho narrado así como enfatizar algunas ideas y excluir o minimizar otras. En ocasiones, cuando existe una cierta regularidad en el tratamiento de un tema determinado, se recurre a fuentes de información también habituales. De este modo, los medios aseguran continuidad y homogeneidad a la visión del mundo presentada, naturalizando determinados discursos y aportando también a la economía de la construcción de la información (15).

En el discurso de la prensa se entrecruzan y superponen diversas formas informativas (crónicas), narrativas (noticias sobre la vida cotidiana, con descripciones y anécdotas) y argumentales (columnas de opinión, editoriales) que, en ocasiones, van acompañadas de materiales ilustrativos, los cuales buscan mostrar la relevancia del tema, lograr un efecto de verosimilitud y, en algunas ocasiones, un efecto de conmoción e impacto $(14,15)$.

La forma en que se articulan estas dimensiones del discurso periodístico expresa el perfil editorial y el posicionamiento de cada medio respecto de la información presentada.

\section{METODOLOGÍA}

La pregunta específica que originó y guió el estudio fue: ¿cuáles fueron las visiones y sentidos atribuidos a la malnutrición infantil por los medios de prensa escrita al calor de la coyuntura crítica dada por la crisis de 2001? Para intentar 
responderla, se utilizó un enfoque cualitativo con un tipo de diseño exploratorio-descriptivo transversal con el objetivo general de analizar la construcción del problema de la malnutrición infantil, identificando las representaciones presentes en los discursos de tres diarios argentinos en un contexto de emergencia social y política.

El tipo de muestra fue no probabilística. La técnica de recolección de la información fue la documental por lo que el corpus estuvo construido a partir de fuentes secundarias dadas por las propias noticias, en tanto se producen con objetivos diferentes a los de la investigación pero susceptibles de ser analizadas con fines investigativos.

La selección de los medios y de las notas publicadas fue intencional. Los criterios de inclusión para la selección de los medios analizados fueron: que tuvieran circulación nacional y frecuencia diaria, y que fueran los de mayor tiraje; que tuvieran perfiles editoriales diferenciados $y$, por ende, que estuvieran dirigidos a diferentes públicos. Se buscaba de este modo la mayor heterogeneidad posible. Los diarios que simultáneamente cumplieron estos criterios fueron $\mathrm{La}$ Nación, Clarín y Crónica, por lo que constituyeron el corpus de análisis.

En relación con la selección de las noticias, el criterio de inclusión fue la referencia temática directa. En otras palabras, se escogió toda aquella noticia publicada en esos tres medios, desde el 20 de diciembre de 2001 hasta el 31 de diciembre de 2002, que mencionara directamente a la malnutrición infantil como tema/problema. Este criterio supuso la recolección de todas las notas periodísticas publicadas durante ese período cuyo agrupamiento temático estuviera dado por menciones a la malnutrición en la población infantil de nuestro país, sus causas y consecuencias, su magnitud y las intervenciones Ilevadas a cabo. El recorte temporal específico se realizó considerando dentro del mismo período (2001-2002) un primer punto de corte establecido el 20 de diciembre de 2001, fecha en que se produce la renuncia del entonces presidente de la nación por considerarla un hito que marcó la crisis en términos institucionales, políticos y sociales; mientras que el cierre del período se estableció el 31 de diciembre de 2002, con el objetivo de observar si hubo publicaciones de notas referidas a la Ley $N^{\circ} 25.724$ (d) y a su proceso de sanción (sancionada el 27 de diciembre de 2002), teniendo en cuenta que se constituyó en una de las respuestas políticas frente al problema y en cuyo proceso ha incidido activamente uno de los medios analizados a través de la campaña "El hambre más urgente".

El corpus de análisis completo quedó constituido por 690 artículos (notas periodísticas, columnas de opinión, editoriales y reportajes), distribuidos de la siguiente manera: 297 artículos del diario La Nación; 212 artículos del diario Clarín y 181 artículos del diario Crónica (e) (Cuadro 1). El procesamiento y análisis de la información se realizó bajo la metodología del análisis del discurso, utilizando soporte informático para el procesamiento (Nvivo 1.3).

Se consideraron los textos insertos en un contexto discursivo (el periodístico) y social (el contexto socio-histórico, la crisis de 2001) específico, intentando producir descripciones a

Cuadro 1. Distribución de las notas periodísticas referidas a malnutrición publicadas en los diarios La Nación, Clarín y Crónica, según el género. Argentina, diciembre de 2001-diciembre de 2002 (n=690).

\begin{tabular}{lcccc}
\hline Géneros & La Nación & Clarín & Crónica & Totales \\
\hline Notas informativas & 259 & 176 & 181 & 616 \\
Columnas de opinión & 22 & 19 & - & 41 \\
Editoriales & 11 & 15 & - & 26 \\
Reportajes & 5 & 2 & 181 & 7 \\
Totales & 297 & 212 & & 690 \\
\hline
\end{tabular}

Fuente: Elaboración propia. 
partir de dos dimensiones principales: la de los enunciados presentes en cada uno de los textos y la de las estrategias para producirlos, partiendo de los aspectos teóricos y contextuales que suministraron datos imprescindibles para el acercamiento a los textos y para su posterior análisis e interpretación. De este modo, en una primera instancia se apeló a la fragmentación de cada uno de los documentos en unidades de codificación para su agrupamiento en categorías generales que respondieran a las siguientes preguntas: ¿cuál es el perfil nutricional que predomina en los tres medios?; ¿qué causas (socioeconómicas, políticas, culturales, psicológicas, biológicas) le atribuyen prioritariamente?; ¿qué consecuencias (biológicas, sociales, políticas) describen?; ¿cuál es la magnitud del problema, en términos de cantidad de afectados?; ¿cómo se enuncia la población afectada?; ¿qué otros actores aparecen prioritariamente involucrados en el problema y cómo se caracterizan sus intervenciones?; ¿cómo se enuncia la sanción de la Ley $N^{0} 25.724$ teniendo en cuenta que se constituyó en una de las iniciativas del Estado en el contexto seleccionado para el análisis?; ¿qué posicionamientos pueden reconstruirse con relación a la política social alimentaria? Simultáneamente, se analizaron los aspectos ligados a las estrategias retóricas y estilísticas más relevantes, consideradas ejes que transversalizan los textos periodísticos y que dan cuenta de la relevancia del tema y de la modalidad enunciativa asumida (géneros predominantes, ubicación en secciones, utilización de fuentes, serialización, utilización de imágenes, etc.).

\section{PRINCIPALES RESULTADOS}

Por la fuerza del contexto, el problema de la malnutrición cobró visibilidad social y política, ingresando en la agenda gubernamental y expresándose tanto a nivel jurídico como institucional, principalmente a través de la presentación de proyectos de ley, sanciones de leyes, firma de decretos y resoluciones, reformulación y reorganización de programas, implementación de medidas específicas, etc. También por la fuerza del contexto, y al igual que en otros casos en los que los medios de comunicación logran instalar temas y sostener debates, la malnutrición infantil ha sido amplia y extensamente tratada por los tres medios analizados durante el período histórico seleccionado. Esto se ha evidenciado a partir de la gran cantidad de información referida al tema en términos de cantidad, extensión de los artículos, cantidad de tapas y sostenimiento en el tiempo, dando cuenta de su relevancia durante ese período. Al respecto, el tema aparece en los tres medios en el primer semestre de 2002, y gana espacio en el segundo semestre. En los tres casos, el mes de noviembre constituyó el mes en el que se publicó la mayor cantidad de noticias referidas al mismo. El caso de La Nación es significativo ya que prácticamente en todas las ediciones del mes publicó al menos una nota relacionada con el problema en tanto impulsor de la campaña "El hambre más urgente", y dos suplementos especiales titulados "El hambre en la Argentina" y "Desnutrición infantil" (el 1 de junio y 12 de octubre, respectivamente).

Pero no solo en términos de agenda ha existido uniformidad entre los tres diarios; sino también en las estrategias periodísticas para el tratamiento mismo de la información: la ubicación del tema en la sección de "interés general" o "sociedad" asumiéndolo como problema que incumbe a la sociedad en su conjunto, se erige como una regularidad. Que el tema haya sido ubicado primordialmente en esta sección, en tanto forma de clasificación, también tiene correlación con los géneros desde los que se ha trabajado el problema: prevalece en las notas informativas, en la forma de crónicas o narrativas, en desmedro de otro tipo de géneros como las columnas de opinión o los editoriales (Cuadro 1). Asimismo, el tratamiento serializado (su sostenimiento en el tiempo), la apelación a estadísticas poblacionales pero también, y especialmente, a casos individuales que generan estremecimiento, la difusión y discusión de las principales medidas implementadas, la regularidad en la apelación a fuentes informativas (personal médico, funcionarios gubernamentales, líderes de organizaciones sociales, técnicos), la utilización de imágenes impactantes y conmovedoras, constituyeron otros aspectos regulares en los tres diarios analizados, dando cuenta de algunas de las características que asume el propio discurso de la prensa y que han sido esbozadas precedentemente. 
Pero además, y a pesar de las diferencias en los perfiles editoriales de cada uno de los medios analizados (f), el contenido de la información también los ubicó en planos similares: el perfil nutricional dominante fue el de la desnutrición aguda y la crónica por falta de alimentos, aun en contra de los datos epidemiológicos producidos durante el período (g).

Que los datos sean oficiales ya no extraña en esta Tucumán donde [...] alguien corrió el velo de una realidad desgarradora para no cerrarlo más: el que ocultaba los ojos grandes de criaturas esqueléticas, faltas de alimentación y de justicia social. (Nota informativa) (17)

Lo que el hambre hizo en [D. A. R.] no es sólo doloroso. Es infame. Tiene cinco años y pesa apenas siete kilos. No mide más de 60 centímetros y apenas puede tenerse en pie. [D.] es otra víctima de la pobreza cruel, indigna. Forma parte de un ejército de chicos hambreados [...]. (Nota informativa) (18)

[A.] es chiquitita, flaquita, pero nada apaga el briIlo de sus ojos. Pide una y otra vez que le saquen una foto [...]. (Nota informativa) (19)

La imagen de [D.], la menor salteña convertida por el hambre en un espectro, con sus costillas a flor de piel y la mirada alucinada, es un patético reflejo de lo que sufren las poblaciones del olvidado Noroeste. (20)

La miseria sigue haciendo estragos en todas las regiones del país, desde el noroeste donde una nena de seis años permanece hospitalizada por desnutrición aguda con sólo cuatro kilos de peso [...]. (20)

Las estrategias desplegadas para el tratamiento de la información también fueron similares: prevaleció en los tres medios un enfoque de la desnutrición -aguda y crónica- como si fuera una enfermedad "infectocontagiosa", que se propaga, que se extiende y contra la que hay que luchar, basándose en la conmoción y en la compasión más que en la argumentación o la información epidemiológica:
El hambre es otro frente que tiene en jaque a [M.

A.] La desnutrición avanza un paso cuando puede. (Nota informativa) (21)

El hambre acecha en San Juan. (Titular) (22)

Allí se vieron severos casos de desnutrición que obligaron a los médicos a efectuar tareas preventivas para evitar que la desnutrición avance. (23)

Desnutrición avanza sin control en el norte. (Titular) (24)

Al relatar el problema de esta manera, como una enfermedad que avanza sin control, la utilización del lenguaje bélico fue su complemento para referirse al problema, a situaciones o a intervenciones:

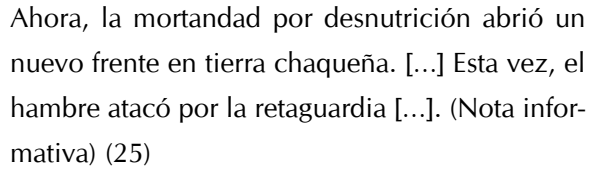

Ahora, la mortandad por desnutrición abrió un nuevo frente en tierra chaqueña. [...] Esta vez, el hambre atacó por la retaguardia [...]. (Nota informativa) (25)

...los efectos de la desnutrición infantil que mató dieciséis chicos y tiene a otros diez en peligro. (26)

Al cumplir tres años al frente de una de las provincias más conflictivas, [...] el gobernador Julio Miranda sabía que su gestión mostraba más falencias que aciertos. Pero no esperaba que, pocos días después, la muerte de 11 niños por desnutrición se transformaría en una bomba que le explotó en pleno rostro. (Nota informativa) (27)

La dura pelea de los guerreros del mate cocido. (Titular) (28)

Salta dará batalla al hambre. (Titular) (29)

Además de textos narrativizados, también las imágenes certificadoras fueron otro de los recursos utilizados para abordar el problema en su totalidad. La exposición de los cuerpos enflaquecidos de estos niños y niñas en la cama de un hospital o en el contexto donde desenvuelven su vida, se mostró como espacio de lo horrible, simbolizando lo infeliz y alienante, aquello que para la sociedad no está resuelto, es inexplicable e incomprensible $y$, por tanto, revela su 
precariedad (30). Así, los casos de desnutrición y muerte fueron presentados con nombre y apellido; las niñas y niños fueron definidos por su peso y talla, construidos como las víctimas del hambre, acompañados de imágenes certificadoras, constituyendo un acercamiento al problema a través de la pena y el impacto.

La causa principal de la malnutrición para los tres medios fue la pobreza. Así, la desnutrición se constituye en una enfermedad de las privaciones, de la pobreza por falta de alimentos. Pero si bien la pobreza, como expresión de la crisis que se estaba viviendo, fue presentada como la causa más inmediata de esta precariedad difícil de comprender en un país prolífico en la producción de alimentos, tematizado como "granero del mundo", desde su dimensión biológica, se estableció una relación directa y mecanicista entre pobreza, inaccesibilidad a los alimentos, hambre y desnutrición, oscureciendo la relación entre la pobreza y la distribución y/o asignación de los recursos sociales y entre la relación asimétrica entre disponibilidad y accesibilidad a los alimentos.

Las muertes por desnutrición infantil no cesan y crecen los índices en un país que cuenta con la mayor cantidad de alimentos por habitante del mundo. (31)

...se producen 70 millones de toneladas de granos por año, que se traducirían en dos toneladas por habitante. Más aún: ¡con sólo el 4 por ciento de nuestras exportaciones de soja acabamos con el flagelo! La Argentina, desde el actual pozo en que se encuentra, produce alimentos para 320 millones de personas. ¿Cómo es posible que haya hambre, entonces? (Editorial) (32)

En el país de la abundancia hay mesas a las que no llega la comida. (Titular, Suplemento Solidario) (33)

En el "granero del mundo" hay hambre. A pesar de las cosechas y exportaciones récords de granos, carnes y alimentos, la pobreza golpea a 20 millones de argentinos. (Nota informativa) (34)

Esta construcción de la pobreza en un país plagado de "riqueza", trajo como consecuencia una construcción dominante de los pobres como necesitados de alimentos y como pasivos, dependientes y carentes; minimizando los saberes y las prácticas desplegadas en relación con su alimentación y salud $(5,6,35,36)$ o calificándolas negativamente. En el discurso de los medios analizados, a partir de un caso, se establece que la "mayoría" de los pobres saben poco acerca de cómo alimentar a sus hijos y cómo cuidarlos; o que no pueden hacerlo. Carecen de ingresos, de trabajos, de alimentos, de capacitación, de información:

La joven madre tiene la tenencia y generalmente los alimenta en el comedor comunitario que funciona en el barrio [...] pero la mayoría de las veces los chicos van solos en busca de algo para comer. (Nota informativa) (37)

Según constató LA NACIÓN [...] los conceptos de cena, desayuno y merienda desaparecieron de las dietas de muchos tucumanos. Es que sólo alcanza para comer una vez al día, y cuando hay trabajo [...]. (Nota informativa) (38)

La falta de trabajo lleva al hambre, al hacinamiento, a la posibilidad de contraer todo tipo de enfermedades. A esto hay que sumarle, [...] la imposibilidad de acceder a centros de salud que, combinado con la falta de información o educación, hace que muchos padres no se den cuenta de que ellos mismos o sus hijos están desnutridos o enfermos. (Nota informativa) (39)

En buena parte de la raíz de este mal está la falta de educación de la mayoría de los sectores pobres e indigentes de nuestro país. No sólo nos sorprende advertir hoy el grado de miseria en que viven familias enteras, sino mucho más su escasa capacitación para proveer de alimentos a sus hijos o para desarrollar pequeñas huertas familiares que ayudarían a resolver elementales problemas de los más necesitados. (Editorial) (40)

Los pobres deben ser "rescatados" por los servicios de salud, especialmente por la abnegación de los profesionales médicos, únicos a los que se excluye de la crítica; o por programas asistenciales eficaces, transparentes, controlados, etc.

El reconocimiento de la dimensión social del problema y la ubicación en el contexto 
social en el que se inscribe, oscureció la dimensión económica del mismo -en términos de desigualdad- y las explicaciones se buscaron en el mundo de la política, representada solamente por la "clase política": entre la pobreza y la riqueza, el deficiente accionar de las agencias del Estado en la gestión y distribución de los programas y los recursos y la dirigencia como un todo, sea por impericia, sea por corrupción.

Es en la caracterización de algunos actores y su rol en las estrategias de intervención donde pueden observarse algunas diferencias de posicionamiento en los tres medios analizados, que podrían asociarse con sus perfiles editoriales. Así, mientras para La Nación el Estado es ineficaz en la gestión de programas alimentarios y debería transferir estas funciones a las organizaciones no gubernamentales, para Clarín el Estado es ineficaz o asume una baja calidad de gestión, pero es necesario.

La comida está: es mucha y es buena. Lo que falta es capacidad de gestión y [...] un interés genuino en resolver el problema. (Editorial) (41)

El Estado ha probado sobradamente su incapacidad y su falta de voluntad para actuar eficazmente en la búsqueda de toda solución que no vaya de la mano del asistencialismo prebendario o del canje por votos. (Editorial) (42)

También aparecen legítimos motivos para dudar acerca de los planes elaborados y de las abundantes consignas inventadas, de discutible validez práctica. El Estado no parece hallar su rumbo y tal vez necesita que entidades más eficientes consigan marcárselo. (Editorial) (43)

...la responsabilidad de que haya chicos desnutridos en el país debe buscarse en la crisis económica y en las deficiencias políticas [...] La corrupción, la ineficiencia y la crisis política han sido, en buena medida, responsables de que se Ilegara a padecer tanto sufrimiento en nuestra sociedad [...]. (Editorial) (44)

Combatir el hambre debe ser la primera prioridad nacional y acabar con la desnutrición infantil, la tarea más urgente. Para ello es preciso que se movilicen todos los recursos del Estado y de la sociedad, materiales y organizacionales, imprescindibles para terminar con esta afrenta a la dignidad humana. (Editorial) (45)

En este marco y como contracara cobraron importancia, especialmente para el diario $\mathrm{La}$ Nación aunque no menos importante para Clarín, la difusión de las medidas asistenciales realizadas por otros actores, como la Iglesia, las organizaciones no gubernamentales y hasta los empresarios solidarios, según postulados neofilantrópicos regidos por la lógica de la buena voluntad y del merecimiento que intervienen de manera transparente y eficiente.

\footnotetext{
...basta con observar el comportamiento de algunas organizaciones no gubernamentales que gestionan, organizan y administran eficientemente la ayuda a los sectores más afectados por la pobreza, logrando [...] que numerosas personas se mantengan bien alimentadas. (Editorial) (41)
}

Es incomprensible que eso ocurra en un país en el que la solidaridad de la gente, de los productores y de las empresas está disponible, a la espera de que los engranajes del poder público aporten la capacidad de organización necesaria. (Editorial) (42)

Es fundamental incorporar sistemáticamente a las múltiples organizaciones de la sociedad civil que ya se ocupan del tema [...] La única manera eficaz de evitar distorsiones y desvíos en la utilización de fondos de asistencia así como los abusos de personajes inescrupulosos [...] es involucrar de lleno a la sociedad en el control de la gestión [...] de los recursos sociales. (Editorial) (45)

En contrapartida, Crónica ha dejado poco lugar para problematizar el rol del Estado, o la eficacia o transparencia en la gestión de los recursos. Como "portavoz del pueblo", su demanda es acabar con la "miseria", sin importar quiénes deberían hacerlo. De manera similar, también opacó la acción de las organizaciones y directamente excluyó a los empresarios. Y a diferencia de Clarín y La Nación que consideraron el potencial peligro que podría implicar la situación de pobreza y de indigencia retrotrayéndose a las clases peligrosas del siglo XIX, Crónica registró, 
por el contrario, su acción reivindicativa -en términos colectivos y no individuales- a través de sus marchas, repudiando y reclamando básicamente comida y puestos de trabajo.

Más allá de los posicionamientos que han tenido en relación con cada uno de los actores involucrados en el problema, los tres medios han actuado corporativamente, enalteciendo el rol de los medios de comunicación en general y de la prensa escrita en particular, en la puesta a consideración de los problemas que incumben a la sociedad, aunque no sin diferencias. En un extremo se colocó La Nación, imponiendo los términos del debate, motorizando a la vez que definiendo las posibles soluciones junto con aliados congruentes con las ideas pregonadas, como un testigo comprometido con la causa (46). La campaña "El hambre más urgente" fue la cristalización de su posicionamiento en relación con el problema, con lo que debería hacerse y quiénes deberían hacerlo. Dicha campaña comenzó a fines del mes de agosto de 2002 y su objetivo consistía en lograr el tratamiento legislativo de un proyecto de ley impulsado por el Grupo Sophia, la Red Solidaria, Poder Ciudadano, el periodista Luis Majul y el diario La Nación. Informó sobre esta iniciativa e incentivó su apoyo, dedicando gran espacio en la mayoría de sus ediciones a la trascripción del proyecto de ley que se impulsaba, al proceso acerca de la consideración por parte del Poder Legislativo de las denominadas iniciativas populares para llegar al tratamiento de las mismas, a las formas de adherir, a las adhesiones que iba suscitando, a las audiencias públicas a las que convocó abiertamente, al proceso de recolección de firmas. $\mathrm{Al}$ respecto, no solo fue un activo impulsor de la campaña y del proyecto que proponían sancionar, sino que, al igual que Clarín, difundió la sanción de la Ley № 25.724 como producto de la iniciativa popular y mediática impulsada, restando importancia a las discusiones que desde diferentes ámbitos despertaba el proyecto y a la existencia de otras propuestas legislativas relacionadas con el problema que se fueron presentando a lo largo de ese año, específicamente el proyecto de ley que el 27 de diciembre de 2002 se convirtió en la ley definitiva.

Como marco general cabe mencionar que a diferencia del protagonismo activo de La Nación en los últimos meses del período analizado en relación con el problema y las intervenciones que impulsaba, Clarín y Crónica tuvieron una actitud menos comprometida con la acción aunque no con las palabras. La opacidad fue la estrategia más utilizada, aunque no la única, en el caso de Clarín para conseguir instalar el debate, congruente con su estilo. En el otro extremo, la lucha a favor del pueblo, como colectivo que aglutina a los sectores populares y sin necesidad de apelar a principios doctrinarios, fue la estrategia más utilizada en el caso de Crónica; su estandarte, "firme junto al pueblo", es su mejor caracterización.

En LA NACIÓN, como prolongación activa de nuestra política editorial, no queremos ser neutros informantes de la angustiante realidad que nos golpea día tras día. Como medio de comunicación no sólo queremos dar cuenta de la realidad, sino también mover a la acción superadora de tantos males que afectan a la sociedad argentina. (Nota informativa) (47)

El grupo se puso en marcha en diciembre al ver las noticias sobre Argentina. (Nota informativa) (48)

La nota tuvo tal repercusión en mi país que un grupo de ciudadanos sintieron la necesidad de ayudar. (Nota informativa) (49)

Las imágenes y la información veraz y minuciosa ofrecidas por Crónica produjeron, en todos los estratos de la sociedad y en lo más alto de los poderes constituidos, una indisimulable conmoción, solo equiparable al estupor que cualquier ciudadano de cualquier nación del mundo civilizado experimentaría al tener que asistir, en un país generoso en nutrientes, a la muerte de sus hijos por desnutrición. Lo dijimos primero, aunque duela [...]. (50)

Los posicionamientos de estos medios deben ponerse en relación con las definiciones que sobre el problema fueron puestas en juego por otros actores sociales durante el mismo período ya que se considera que la construcción de un problema y las definiciones sobre el mismo no son meras construcciones de los documentos publicados por la prensa escrita. Podría afirmarse que recogen esas definiciones de todo un cúmulo 
de actores (médicos, nutricionistas, especialistas en políticas sociales, funcionarios, afectados por el problema, etc.) devenidos, en ocasiones, en sus fuentes informativas, como una mirada-síntoma -diría Sidicaro (46)-, y las actualizan, reproduciéndolas de acuerdo con las reglas que definen al discurso periodístico. Hay, en este sentido, una relación dinámica -por la fuerza de los acontecimientos- en la que se entrecruzan las voces de todos los actores que los diarios consideran que están involucrados. Pero esa relación dinámica también se establece en el sentido inverso. Así, en argumentos de legisladores, en discursos de políticos, en palabras de líderes sociales, los medios de comunicación han aparecido como fuentes para las argumentaciones, como reveladores de situaciones, como denunciantes de injusticias, como actores protagónicos en la visibilización del problema.

En esta co-construcción puesta en evidencia durante este proceso se actualizaron determinadas representaciones que no solo dan cuenta de aspectos que podrían calificarse de restringidos (perfil nutricional dominante, causas, consecuencias, actores directamente involucrados), sino que dan cuenta de la organización social en su conjunto. En otras palabras, en la construcción de la malnutrición confluyeron representaciones sobre la enfermedad y el cuerpo enfermo, pero también sobre la alimentación, las medidas necesarias para "resolverla", sobre los actores y las instituciones involucrados y hasta sobre el modelo productivo. Así, las representaciones recurrentes que organizaron los discursos constituyeron una trama argumental, basada en ciertas homologías y rupturas, que se sintetizan a continuación:

- La Argentina como país históricamente prolífico en la producción de alimentos, a través de la metáfora del "granero del mundo".

- La Argentina como país sumido en una grave crisis social, económica y política, leída como contexto crítico, catastrófico.

- La malnutrición, especialmente la desnutrición aguda y la desnutrición crónica, ligada con un problema de acceso a los alimentos (prioritariamente en términos de cantidad) y, por ende, como consecuencia de la pobreza.
- La tematización de la pobreza como símbolo de flaqueza producto del hambre y la carencia, basada principalmente en la definición de la alimentación como necesidad biológica y de manera minoritaria en la definición política de la alimentación como derecho, dando cuenta de dos tipos de argumentos con fuertes implicancias a la hora de pensar las intervenciones en materia de políticas.

- Las medidas en relación con el problema como lucha encarnizada, a través de la metáfora de la guerra: lucha, pelea, combate, batalla, rastrillajes, fueron diferentes términos propios del lenguaje militar tan utilizado en el discurso biomédico. Alimentación y salud, como hechos sociales complejos, se vieron restringidos a dos objetos: alimentos y medicamentos. Dar de comer constituyó "la" medida que sintetizó la estrategia en esta guerra.

- Otros dos grupos de representaciones en relación con los actores capaces (o incapaces) de "enfrentar" este problema: el Estado, como ineficaz e ineficiente en esta lucha, debería dejar lugar a las organizaciones de la sociedad civil; y el Estado como garante último de los derechos vinculados a la alimentación que debería actuar coordinadamente con otros actores sociales.

\section{DISCUSIÓN}

¿Cómo puede comprenderse que las estrategias periodísticas desplegadas para informar sobre el problema hayan sido similares en medios con perfiles editoriales tan diferentes?

Según Bourdieu (51), la uniformidad de los productos periodísticos podría explicarse como consecuencia de los constreñimientos impuestos por las fuentes y por la puesta en acto de una serie de mecanismos propios de la lógica del campo periodístico, entre los cuales el de mayor importancia es la lógica de la competencia entre los profesionales de los medios, y por el sometimiento del propio campo periodístico a la lógica del campo económico. En este último sentido, la lucha no se da tanto por el capital cultural sino por el capital económico, coadyuvado a 
su vez por el dominio de la lógica del juego periodístico, que los periodistas adquieren por la experiencia en ese juego y que funciona más allá de la conciencia y el discurso: hacen lo que tienen que hacer, lo que demanda y exige el juego en la medida que poseen intereses comunes vinculados a su posición dentro del campo y que comparten unas estructuras cognitivas y unas categorías de percepción y de valoración ligadas a sus trayectorias sociales y profesionales.

Lo que demanda y exige el juego dentro del campo está regido por la lógica de la competencia entre periodistas para captar lectores. En un campo orientado hacia la producción de bienes perecederos como las noticias, la competencia tiende a adoptar la forma de una competencia por la primicia, lo cual incita a ejercer una vigilancia permanente de las actividades de otros periodistas y de otros medios, tratando de recurrir a similares estrategias: temas de números especiales que hay que imitar, columnistas que hay que tener $y / o$ convocar, temas que hay que cubrir porque otros los han cubierto. Así, las decisiones sobre qué es importante y qué merece ser transmitido, procede no solo de las fuentes (oficiales y no oficiales) sino de los propios informadores. Estos procesos de interlecturas, exigencia tácita de la profesión, hacen que se trate de un verdadero "juego de espejos", un proceso de circulación circular de la información. Por lo tanto, la competencia entre los profesionales de las noticias, lejos de originar originalidad, tiende a menudo a favorecer la uniformidad de la oferta periodística, en relación con lo que es definido como noticia, con los hechos a cubrir y con el estilo y los formatos a través de los cuales se relata un hecho.

A los intereses económicos y empresariales que regularían la actividad, y a las lógicas propias del campo periodístico que uniformarían qué y cómo relatar aquello que es definido como noticiable, debe sumarse otra dimensión del análisis relacionada con las representaciones que subyacen a la hora de abordar el problema, contribuyendo a su construcción y/o reproducción, como quedó dicho en el apartado precedente. En el tratamiento del tema se evidenció la presencia de representaciones ligadas con el problema que trasciende la lógica del discurso periodístico y que ponen en evidencia tramas argumentales que sustentan la construcción de un problema.
En este sentido, cabe otra pregunta relacionada ya no con las estrategias propias del discurso periodístico sino con los contenidos mismos. Es decir, ¿cómo pueden comprenderse ciertas representaciones que organizaron esos mismos discursos? Abordarlas desde las trasposiciones metafóricas utilizadas (h) puede ofrecer indicios para comprender las razones de algunas persistencias.

Varias son las metáforas que han sido reactualizadas al hablar de la malnutrición infantil y de sus expresiones, pero las más sistemáticamente utilizadas fueron la Argentina como "granero del mundo" y las intervenciones como estrategias o tácticas en el marco de una guerra. Ambas organizaron gran parte de la trama argumental desplegada.

La metáfora del "granero del mundo", fue utilizada por primera vez en los primeros años del 1900, en pleno auge del modelo agroexportador argentino. Esta operación discursiva oscurece y obtura la comprensión de los cambios producidos a lo largo de casi un siglo: en la organización productiva, en la estructura social, en el tipo de productos que se produce, en la relación asimétrica entre disponibilidad y acceso a los alimentos (35). Si bien es cierto que Argentina puede producir alimentos en cantidad y calidad suficientes, también es cierto que esta potencialidad está en riesgo ya que lo que está en cuestión es si se puede seguir haciéndolo en la cantidad y con la diversidad necesarias $(6,35,53)$. En otras palabras, lo que está en juego es la sustentabilidad productiva, y esto ha sido excluido del debate. Por otro lado, la metáfora del "granero del mundo" sigue obturando la comprensión de la relación entre disponibilidad de alimentos y acceso a los mismos en términos de desigualdad en la distribución del ingreso social. Frente a la desgracia de "ya no ser", la explicación se va buscando en otro lado, principalmente en la situación de crisis, culpabilizando especialmente a la clase política y al modelo implementado en los años '90. En este sentido, la crisis se sustancializó, como sucedió en los '90, como se sustancializó la clase política y la crisis de representación ligada a ella, quedando poco juego para reconocer el papel de los actores pensados individual y colectivamente. La crisis es la consecuencia de un proceso histórico político-económico. Como tal, al igual que en otros momentos, otorgó el 
fundamento y factor explicativo para el reconocimiento del problema. Pero el peligro de operar en la crisis "sustancializada" es quedarse en la coyuntura, debatir y actuar en la emergencia, dando respuestas tendientes a solucionar los efectos y no debatir e intervenir sobre las causas.

La tematización de la pobreza como efecto de la crisis y entendida desde una perspectiva biologicista y mecanicista, sumado a la caracterización dominante de los pobres como pasivos y como necesitados de alimentos, ha obturado la comprensión de la compleja configuración de los consumos de estos actores en relación con la incidencia de sus propias estrategias $(5,6,35,36)$, de los programas del Estado, de las iniciativas solidarias y del mercado de alimentos en el tipo de alimentos consumidos y sus consecuencias en el patrón nutricional actual $(5,6)$.

Correlativamente a la forma en que se construye la pobreza y a los pobres, hay una concepción predominante de la alimentación y esta concepción aparece vinculada con la definición de la alimentación como necesidad biológica. Si bien se reconoce la dimensión biológica de la alimentación, esta constituye un fenómeno complejo: involucra aspectos biológicos, referidos a las necesidades y capacidades del organismo y a las características de los alimentos; pero también ecológicos y demográficos, referidos a la cantidad y a la calidad de alimentos que se pueden producir en un lugar determinado en relación con la población y su calidad de vida; tecnológicos y económicos, referidos a los circuitos de producción y distribución para el acceso de la población sea a través del mercado, del Estado o de las redes de ayuda mutua; y sociopolíticos y culturales, referidos a las normas de distribución según la clase, la edad y el género además de los tipos de comidas según las diferentes ocasiones (54). En el espacio de la política, considerar solo la dimensión biológica de la alimentación:

...nos coloca en el reduccionismo biológico del mundo social y la lucha político-académica por la definición de los límites de lo "necesario". Asociado a esta definición está el concepto de pobreza como "falta", y los estándares "humanos" de necesidades bajo los cuales no se cubren los requerimientos biológicos, culturales, axiológicos, etc. (6 p.226)
Esta manera de construir el problema en su totalidad (en términos de causas, poblaciones afectadas, intervenciones promovidas) se contradice con el perfil nutricional prevalente. Ya que si bien desde los estudios epidemiológicos se considera la existencia de una inversión en los patrones nutricionales, de la histórica relación material y simbólica entre pobreza-flaqueza y riqueza-gordura a riqueza-flaqueza y pobrezagordura, puede decirse que las representaciones no han ido de la mano de estos perfiles nutricionales (35). Como se ha analizado, aun se mantienen y actualizan las representaciones de la malnutrición ligadas con la falta de alimentos y con la pobreza unida a la flaqueza. Estas representaciones tienen siglos de construcciones y reconstrucciones y no son exclusivas del discurso de los medios. Dichas representaciones sobre el cuerpo en estado sano o el cuerpo en estado enfermo siguen operando hoy, aunque con grandes diferencias según el sector social al que se pertenezca: el cuerpo flaco de los pobres es sinónimo de enfermedad mientras que el cuerpo flaco de los sectores de clase media y media alta es sinónimo no solo de salud sino también de belleza $(6,55)$. Sin embargo, los cuerpos gordos de los pobres también revelan problemáticas nutricionales ligadas con la carencia. El problema es que las consecuencias de la inaccesibilidad alimentaria en la pobreza, como el sobrepeso y la obesidad, siguen siendo menos visibles para la sociedad. Esta visibilidad iría en contra de las intervenciones que en su mayoría se han venido realizando desde diferentes sectores, acarreando consecuencias no solo sanitarias, sino también económicas y políticas. La provisión directa de alimentos no perecederos reproduce los alimentos rendidores que consumen los pobres: son baratos, Ilenan, pero además contienen políticamente (6).

A su vez, los cuerpos flacos de los pobres, como sinónimos de hambre, dan cuenta de representaciones ligadas con el discurso biomédico y, como tal, aparece fuertemente naturalizado. También ligado con el discurso médico están las estrategias de la guerra. La lucha contra las enfermedades ejemplifica la utilización del lenguaje bélico y su transposición al campo de las enfermedades. Según Sontag (56), la metáfora militar apareció en medicina hacia 1880, cuando 
se identificaron las bacterias como agentes patógenos. De ahí la tematización de la malnutrición como enfermedad comportándose como una enfermedad infectocontagiosa: epidemia, propagación, lucha, avance, estragos, etc. De ahí también el silencio respecto de las estrategias de los hogares en relación con la salud y la enfermedad: rastrillaje y rescate constituyen dos acciones para salvar a las víctimas y la figura que encarna la salvación en el campo de la enfermedad es el profesional médico. Como en toda contienda hay víctimas y victimarios, culpas y culpables. Pero, a diferencia de otras enfermedades en las que se responsabiliza directamente a la persona que la padece (el caso del VIH/sida constituye un ejemplo), aquí la culpa aparece disipada entre el modelo neoliberal, la clase política, la "mala" gestión y administración de los recursos, y desde el espacio individual en el agregado doméstico debido a la carencia y a la pasividad que se le atribuye.

Estas visiones se transforman en principios que guían y condicionan las intervenciones en materia de políticas y de promoción de políticas: si se producen alimentos capaces de alimentar a toda la población, "si la comida es mucha y es buena", si se está atravesando una crisis en la que los niños pertenecientes a los sectores pobres e indigentes no están satisfaciendo una necesidad biológica dada por la falta de alimentos y esto se traduce en sus cuerpos, dar de comer es la intervención más eficaz en términos sanitarios y políticos para "luchar" contra la desnutrición.

Así, la ausencia de problematización en relación con el perfil nutricional dominante y sus causas conlleva que las estrategias de intervención promovidas, explícita o tácitamente por los medios, reproduzcan una lógica tan exitosa (en términos económico-políticos) como contraproducente (en términos sanitarios).

Pero no solo las persistencias y regularidades de los discursos son importantes. También las exclusiones, las dilaciones y los silencios. ¿Qué es lo que se minimizó y/o excluyó en esta trama argumental? La alimentación como derecho humano ratificada en diversos documentos (i) y el rol del Estado para su garantía; los cambios producidos en el modelo socioeconómico, la organización productiva y la relación asimétrica entre disponibilidad y acceso; la desigualdad en la distribución del ingreso y la exclusión social; la crisis como consecuencia de un proceso políticoeconómico y las estrategias de los hogares en este contexto; la inversión de los patrones nutricionales y el requerimiento de otro tipo de intervenciones (integrales, intersectoriales). La causa de estas sucesivas omisiones o minimizaciones no fue el desconocimiento. Hablar de derecho a la alimentación implica ciudadanía, y esto se traduce no solo en responsabilidades, compromisos, garantías y obligaciones, leyes y responsables de hacer cumplir esas leyes, sino que también debe traducirse en la redistribución del ingreso (6). Sin embargo, ello implica modificar gran parte de las reglas del juego, $y$, por ende, el poder de ciertos jugadores para imponerlas (9).

\section{PALABRAS FINALES}

Las representaciones condicionan y guían intervenciones. "Dar de comer" constituyó la estrategia de intervención que unificó a los tres medios en estrecha interrelación con la forma en que se ha construido el problema en el contexto crítico de 2001-2002 sustentada también por otros discursos y actores. Pero además de las persistencias y regularidades, las exclusiones, dilaciones y los silencios mencionados en párrafos anteriores, cabe resaltar también las diferencias y rupturas. En otras palabras, el funcionamiento de los medios según las lógicas propias del campo periodístico, según tendencias temáticas y estilísticas unificadoras, no impide el análisis de ciertas particularidades. Así, las visiones y sentidos actualizados en esa propuesta general tienen matices en cada uno ellos, congruentes con sus perfiles editoriales, con las representaciones de sus lectores construidas discursivamente y con los posicionamientos político-ideológicos que defienden y/o promueven: mientras el diario $\mathrm{La}$ Nación propone "El hambre más urgente", gestionado por organizaciones no gubernamentales bajo supuestos neofilantrópicos y bajo el valor de la transparencia y eficacia de estas en contraposición a las agencias del Estado, Clarín propone programas técnicos y no políticos, eficacia y transparencia en la gestión y distribución de prestaciones o "gestión controlada de los recursos 
sociales", pero con la necesaria intervención del Estado y la participación de las organizaciones no gubernamentales y de la sociedad. Finalmente Crónica propone proteger al "pueblo", sin discutir ni criticar los supuestos políticos, técnicos e ideológicos que animan estas medidas, programas y políticas. En la base de estas propuestas subyace la definición de la alimentación como "necesidad biológica". Privilegiar solo esta dimensión oscurece los procesos sociales, políticos y culturales y nos ubica en el mundo de lo biológico. Por el contrario, tenerlos presentes nos permite comprender las consecuencias de la alimentación como producto de determinados modos sociohistóricos de producir, distribuir, acceder y consumir los alimentos. Pero, tanto en lo que se explicita como en lo que se omite, en lo que se define o propone, en lo que se silencia, minimiza o reproduce, el análisis realizado nos aproxima a comprender el carácter social de la alimentación y de sus consecuencias, como construcción social, como producto y productora de relaciones sociales.

\section{NOTAS FINALES}

a. Aunque fue parte de la compilación Obesidad en la pobreza, un nuevo reto para la salud pública, de Peña y Bacallao y editada en el año 2000 por la Organización Panamericana de la Salud y la Organización Mundial de la Salud; "Aspectos socio-antropológicos de la obesidad en la pobreza", es un trabajo escrito en el año 1995.

b. Los objetivos de la Encuesta Nacional de Nutrición y Salud estaban encaminados a obtener información sobre el estado de nutrición y salud de niños y niñas entre 6 meses y 5 años, mujeres en edad fértil y embarazadas; a evaluar factores asociados a los perfiles nutricionales así como a obtener información acerca del acceso de los servicios sanitarios y la cobertura de programas alimentarios en esas poblaciones.

c. Este artículo está basado en la Tesis de Maestría en Políticas Sociales (Facultad de Ciencias Sociales, UBA), titulada "Dar de comer. La construcción social del problema de la malnutrición infantil, desde la perspectiva del Estado y la prensa escrita. Diciembre 2001-diciembre 2002", bajo la dirección de la Dra. Patricia Aguirre. La tesis fue defendida en septiembre de 2009.

d. La Ley $N^{\circ} 25.724$ tuvo su origen en un proyecto presentado en la Cámara de Diputados a mediados de diciembre de 2002. Fue sancionada en la Cámara de Senadores el 27 de diciembre de ese mismo año. A través de ella, se creó el Programa de Nutrición y Alimentación Nacional. Fue publicada en el Boletín Oficial en enero de 2003 y reglamentada a través del Decreto $1.018 / 03$ en abril de 2003. En sus primeros artículos $\left(1^{\circ}\right.$ y $\left.2^{\circ}\right)$ establece la creación del Programa Nacional de Nutrición y Alimentación (que luego fue denominado Plan Nacional de Seguridad
Alimentaria) "en cumplimiento del deber indelegable del Estado de garantizar el derecho a la alimentación de toda la ciudadanía" (16). En la ley se establece que "Dicho Programa en la emergencia, está destinado a cubrir los requisitos nutricionales de niños hasta los 14 años, embarazadas, discapacitados y ancianos desde los 70 años en situación de pobreza [...] se prioriza a las mujeres embarazadas y a los niños hasta los 5 (cinco) años de edad" (16). Establece diferentes acciones acordes con el nivel jurisdiccional correspondiente (nacional, provincial y municipal). Algunas de las acciones previstas son las siguientes: prestaciones alimentarias y cuidado de la salud, educación alimentaria nutricional, un sistema de evaluación permanente del estado nutricional de la población, capacitación de las familias en nutrición, promoción de la lactancia materna, desarrollo infantil y economato, estímulo de la producción alimentaria regional a fin de abastecer de los insumos necesarios a los programas de asistencia alimentaria locales, entre otras acciones. Disponía también la unificación y coordinación de todos los programas vigentes para evitar la superposición de partidas presupuestadas, a los efectos de "desterrar la desnutrición en todo el territorio nacional" (16).

e. A diferencia de La Nación y Clarín, Crónica no apela a la diversidad de los géneros periodísticos en ninguno de los temas trabajados. Si se consideran las tipificaciones establecidas en este trabajo (nota informativa, columna de opinión, editorial y reportaje), podría afirmarse que la nota informativa constituye el único género periodístico de Crónica. Esto no es exclusivo de las notas referidas al tema que aquí se estudia. La mayoría de los temas se trabajan siguiendo las reglas de este género. Al respecto, la edición que se analizó (la Sexta Edición), no trabaja desde el género editorial. Si bien es en los editoriales donde puede observarse la asunción explícita de determinada 
posición, esto no invalida la reconstrucción de posiciones a partir del análisis de este otro género, habida cuenta de que la selección y enfoque del problema, de las fuentes convocadas y de su particular forma de informar, permiten reconstruir las formas implícitas de posicionamiento.

f. El diario La Nación ha sido tradicionalmente el órgano difusor de las ideas representativas de los sectores de clase alta y media alta argentinos: defensores de los intereses del sector agroexportador, conservadores en lo político y liberales en lo económico. El diario Clarín ha sido tradicionalmente el órgano difusor de las ideas representativas de los sectores de clase media urbana, bregando históricamente por los intereses de la burguesía nacional. Crónica se erige como el órgano representativo de los sectores populares, constituyéndose en portavoz del pueblo, con sus avatares, desdichas y reivindicaciones y hacia él se dirige y apoya. Históricamente se lo ha ubicado dentro de la denominada prensa sensacionalista.

g. Las citas de los fragmentos son el resultado de una selección a partir de la cual se volcaron aquellas que expresan de manera más contundente las ideas presentadas. Tienen la función de apoyar y sustentar las afirmaciones que surgen del análisis. Si bien en las notas periodísticas se publicó el nombre completo de los niños y niñas afectados, en las citas textuales que se seleccionaron para la ejemplificación se decidió solo escribir sus iniciales con el objetivo de no vulnerar nuevamente el derecho a la preservación de su identidad.

h. La metáfora es una figura retórica que consiste en dar a una cosa el nombre de otra, y se constituye en una operación de conocimiento ampliamente extendida, tanto en el uso cotidiano del lenguaje como en el discurso científico. Pero estos recursos del lenguaje no siempre son operaciones retóricas creativas, sino que en ocasiones ordenan, fijan, naturalizan y bloquean (52) determinados procesos sociales. Por lo tanto, es necesario ponerlas en evidencia, criticarlas, rastrear su historia, para desentrañar la operación discursiva que conlleva su utilización y naturalización.

i. La Convención de los Derechos del Niño se aprobó a partir de la sanción de la Ley No 23.849 en 1990 y se incorporó a la Constitución Nacional con la reforma de 1994; la Declaración Mundial sobre Nutrición y el Plan de Acción para la Nutrición elaborados en la primera Conferencia Internacional de Nutrición en 1992; la Declaración de Roma sobre Seguridad Alimentaria Mundial y el Plan de Acción de la Cumbre Mundial de la Alimentación elaborados en la Conferencia Internacional de Seguridad Alimentaria en 1996; entre otros documentos.

\section{REFERENCIAS BIBLIOGRÁFICAS}

1. García Delgado D. Estado-Nación y la crisis del modelo. Buenos Aires: Grupo Editorial Norma; 2003.

2. Svampa M. La sociedad excluyente. Buenos Aires: Taurus; 2005.

3. Instituto Nacional de Estadística y Censos. Línea de Pobreza y Canasta Básica. Serie Histórica. Porcentaje de hogares y personas bajo las líneas de pobreza e indigencia en los aglomerados urbanos y regiones estadísticas, desde mayo 2001 en adelante [Internet] Buenos Aires: INDEC [citado 18 jul 2010]. Disponible en: http://www.indec.mecon.ar/nuevaweb/cuadros/74/sh-pobreza1.xls

4. Aguirre P. Aspectos socioantropológicos de la obesidad en la pobreza. En: Peña M, Bacallao J, compiladores. Obesidad en la pobreza, un nuevo reto para la salud pública. Washington: OPSOMS; 2000. p. 13-26.

5. Calvo E, Aguirre P. Crisis de la seguridad alimentaria en la Argentina y estado nutricional en una población vulnerable. Archivos Argentinos de Pediatría. 2005:103(1):77-90. 
6. Aguirre P. Estrategias de consumo: qué comen los argentinos que comen. Buenos Aires: CIEPP, Miño y Dávila; 2005.

7. Ministerio de Salud de la Nación. Encuesta Nacional de Nutrición y Salud. Documento de Resultados 2007 [Internet]. Buenos Aires: Ministerio de Salud de la Nación; 2007 [citado 18 jul 2010]. Disponible en: http://www.msal.gov.ar/ htm/site/ennys/pdf/ENNyS_Documento-de-resultados-2007-II.pdf

8. Tenti Fanfani E. Pobreza y política social: más allá del neoasistencialismo. En: Isuani E, Lo Vuolo R, Tenti Fanfani E. El Estado Benefactor. Un paradigma en crisis. Buenos Aires: CIEPP, Miño y Dávila; 1991. p. 89-136.

9. Bourdieu P. Espacio social y poder simbólico. En: Cosas dichas. Buenos Aires: Gedisa; 1988. p. 127-142.

10. Grassi E. Política y Cultura. Una aproximación. En: Política y cultura en la sociedad neoliberal. La otra década infame (II). Buenos Aires: Espacio Editorial; 2004. p. 21-46.

11. Aguilar Villanueva L, editor. Problemas públicos y agenda de gobierno. México: Porrúa; 1993.

12. Moro J. Problemas de agenda y problemas de investigación. En: Escolar Cora, compiladora. Topografías de la investigación. Métodos, espacios y prácticas profesionales. Buenos Aires: Eudeba; 2000. p. 113-140.

13. Champagne P. La visión mediática. En: La miseria del mundo. Buenos Aires: Fondo de Cultura Económica; 1999. p. 51-64.

14. Martini S, Luchessi L. Los que hacen la noticia. Buenos Aires: Editorial Biblos; 2004.

15. Martini S. Periodismo, noticia y noticiabilidad. Bogotá: Grupo Editorial Norma; 2004.

16. Ley $N^{o}$ 25.724. Programa de Nutrición y Alimentación Nacional [Internet] Buenos Aires: Honorable Senado de la Nación; 2002 [citado 2 mar 2011]. Disponible en: http://www.senado. gov.ar/web/proyectos/verExpe.php?origen $=\mathrm{CD} \&$ tipo $=$ PL\&numexp $=153 / 02 \&$ nro_comision $=\&$ tC onsulta $=4$

17. Castro A. Tucumán: más de 18.000 desnutridos. La Nación [Internet] 26 nov 2002 [citado 2 mar 2011]. Disponible en: http://www.lanacion.com.ar/453039-tucuman-mas-de-18000desnutridos
18. García Terán M. Son 9000 los chicos con desnutrición en el Chaco. La Nación [Internet] 24 nov 2002 [citado 2 mar 2011]. Disponible en: http://www.lanacion.com.ar/452594-son-9000los-chicos-con-desnutricion-en-el-chaco

19. Laurnagaray G. Historias de hambre, padecimientos y dolor en seis provincias. Clarín [Internet] 20 nov 2002 [citado 2 mar 2011]. Disponible en: http://edant.clarin.com/diario/2002/11/20/s-02802.htm

20. Dramático: desnutrición en el norte y leptospirosis en Quilmes. Crónica (Sexta Edición). 9 jun 2002:28.

21. Palacios C. Una pulseada diaria contra la desnutrición. La Nación [Internet] 1 oct 2002 [citado 2 mar 2011]. Disponible en: http://www.lanacion.com.ar/436550-una-pulseada-diaria-contrala-desnutricion

22. El hambre acecha en San Juan. Clarín [Internet] 30 nov 2002 [citado 2 mar 2011]. Disponible en: http://edant.clarin.com/diario/2002/11/30/s-03401.htm

23. Faltan alimentos, sobran mugre y desidia. Crónica (Sexta Edición). 15 nov 2002:6.

24. Desnutrición avanza sin control en el norte. Crónica (Sexta Edición). 22 nov 2002:8-9.

25. La desnutrición golpeó en el Chaco: murió un bebé de un año. La Nación [Internet] 05 dic 2002 [citado 2 mar 2011]. Disponible en: http://www.lanacion.com.ar/456058-la-desnutricion-golpeo-en-el-chaco-murio-un-bebe-de-un-ano

26. Hambreados saquearon una escuela. Crónica (Sexta Edición). 10 dic 2002:2-3.

27. García Soto F. Un gobernador acorralado que no deja el cargo por temor a la Justicia. La Nación [Internet] 27 nov 2002 [citado 2 mar 2011]. Disponible en: http://www.lanacion.com.ar/ nota.asp?nota_id $=453275$

28. Heguy S. La dura pelea de los guerreros del mate cocido. Clarín [Internet] 17 nov 2002 [citado 2 mar 2011]. Disponible en: http://edant.clarin.com/diario/2002/11/17/s-04415.htm

29. Salta dará batalla al hambre. Crónica (Sexta Edición). 31 dic 2002.

30. Minayo MCS. Etapa de trabajo de campo. En: El desafío del conocimiento. Investigación cualitativa en Salud. 2a ed. Buenos Aires: Lugar Editorial; 2004. p. 91-164. 
31. Murió la piba desnutrida de Chaco. Crónica (Sexta Edición). 25 oct 2002.

32. Aguinis M. Sería posible paliar el hambre en pocas semanas. La Nación [Internet] 21 sep 2002 [citado 2 mar 2010]. Disponible en: http://www.lanacion.com.ar/433581-seria-posible-paliar-el-hambre-en-pocas-semanas

33. Comesaña, J. En el país de la abundancia hay mesas a las que no llega la comida. La Nación (Suplemento Solidario). 1 jun 2002:1.

34. Bermúdez I. Cómo se llegó a la situación de hambre en la Argentina. Clarín [Internet] 18 nov 2002 [citado 2 mar 2010]. Disponible en: http://edant.clarin.com/diario/2002/11/18/s02415.htm

35. Aguirre P. Comida, cocina y consecuencias: la alimentación en Buenos Aires. En: Torrado S, compiladora. Población y bienestar en la Argentina del primero al segundo centenario. Una historia del siglo XX. Buenos Aires: Edhasa; 2007. p. 469-503

36. Menéndez E. Modelos de atención de los padecimientos: de exclusiones teóricas y articulaciones prácticas. En: Spinelli $\mathrm{H}$, compilador. Salud Colectiva: cultura, instituciones y subjetividad; epidemiología, gestión y políticas. Buenos Aires: Lugar Editorial; 2004. p. 11-47.

37. Dos bebés, víctimas de la desnutrición. La Nación [Internet] 24 sep 2002 [citado 2 mar 2011]. Disponible en: http://www.lanacion.com.ar/ 434304-dos-bebes-victimas-de-la-desnutricion

38. Promesas del gobernador Miranda. La Nación [Internet] 17 nov 2002 [citado 2 mar 2011]. Disponible en: http://www.lanacion.com.ar/ 450760-promesas-del-gobernador-miranda

39. Iglesias M. Uno de cada cinco chicos de la Argentina está desnutrido. Clarín [Internet] 17 nov 2002 [citado 2 mar 2011]. Disponible en: http://edant.clarin.com/diario/2002/11/17/s04615.htm

40. Tucumán: desnutrición y clientelismo. La Nación [Internet] 21 nov 2002 [citado 2 mar 2011]. Disponible en: http://www.lanacion.com.ar/ 451631-tucuman-desnutricion-y-clientelismo

41. El hambre, un problema de gestión. La Nación [Internet] 7 jul 2002 [citado 2 mar 2011]. Disponible en: http://www.lanacion.com.ar/ 411616-el-hambre-un-problema-de-gestion

42. El inconcebible problema del hambre. La Nación [Internet] 28 ago 2002 [citado 2 mar 2011].
Disponible en: http://www.lanacion.com.ar/ 426117-el-inconcebible-problema-del-hambre

43. Las víctimas del hambre. La Nación [Internet] 15 nov 2002 [citado 2 mar 2011]. Disponible en: http://www.lanacion.com.ar/450017-las-victimas-del-hambre

44. Tareas para erradicar la desnutrición infantil. Clarín [Internet] 19 nov 2002 [citado 2 mar 2011]. Disponible en: http://edant.clarin.com/diario/2002/11/19/o-02002.htm

45. La necesidad urgente de combatir el hambre. Clarín [Internet] 24 nov 2002 [citado 2 mar 2011]. Disponible en: http://edant.clarin.com/diario/2002/11/24/o-02401.htm

46. Sidicaro R. Consideraciones a propósito de las ideas del diario La Nación. En: Wainerman C, Sautu R, compiladores. La trastienda de la investigación. 3a ed. Buenos Aires: Lumiere; 2004. p. 73-90.

47. Conmoverse y actuar, hoy. La Nación [Internet] 18 sep 2002 [citado 2 mar 2011]. Disponible en: http://www.lanacion.com.ar/431724-conmoversey-actuar-hoy

48. Ayuda argentina desde EE.UU. Clarín [Internet] 15 jul 2002 [citado 2 mar 2011]. Disponible en: http://edant.clarin.com/diario/2002/07/15/s-03003.htm

49. Polémica por un contenedor que llegó de EE.UU. Clarín [Internet] 19 nov 2002 [citado 2 mar 2011]. Disponible en: http://edant.clarin.com/diario/2002/11/19/s-03304.htm

50. Crónica ayer conmocionó al país con sus ediciones vespertinas. Crónica (Sexta Edición). 14 nov 2002:7.

51. Bourdieu P. Sobre la televisión. Barcelona: Anagrama; 1997.

52. Ford A. De la aldea global al conventillo global. En: Navegaciones: Comunicación, cultura y crisis. Buenos Aires: Amorrortu Editores; 1996. p. 42-64.

53. Teubal M. Soja transgénica y crisis del modelo agroalimentario argentino. Realidad Económica [Internet] 2003 [citado 18 jul 2010];(196). Disponible en: http://www.iade.org.ar/modules/ noticias/article.php?storyid $=779$

54. Aguirre P. Ricos flacos y gordos pobres. La alimentación en crisis. Buenos Aires: Capital Intelectual; 2004. 
55. Pinotti L. El modelo estético hegemónico a 56. Sontag S. La enfermedad y sus metáforas. El fin del siglo, patologías que afectan el crecimiensida y sus metáforas. Buenos Aires: Taurus; 2005. to y desarrollo normal. En: Álvarez M, Pinotti L, compiladores. Procesos socioculturales y alimentación. Buenos Aires: Ediciones del Sol; 1997. p. 139-160.

\section{FORMA DE CITAR}

Demonte F. La construcción de la malnutrición infantil en la prensa escrita argentina durante la crisis de 2001. Salud Colectiva. $2011 ; 7(1): 53-71$.

Recibido el 30 de julio de 2010

Versión final presentada el 25 de enero de 2011

Aprobado el 18 de febrero de 2011 